\title{
The Potential Blockchain Technology in Higher Education Learning Innovations in Era 4.0
}

\author{
Primasatria Edastama ${ }^{1}$, Suryari Purnama ${ }^{2}$, Riya Widayanti ${ }^{3}$, Lista Meria $^{4}$, Deva \\ Rivelino ${ }^{5}$
}

\author{
University of Esa Unggul1,2,3,4, Universitas Raharja ${ }^{5}$ \\ Jl. Arjuna Utara No.9, RT.1/RW.2, Duri Kepa, Kec. Kb. Jeruk, Kota Jakarta Barat, Daerah \\ Khusus Ibukota Jakarta ${ }^{1,2,3,4}$ \\ Jl. Jenderal Sudirman No.40, RT.002/RW.006, Cikokol, Kec. Tangerang, Kota Tangerang, \\ Banten, Indonesia ${ }^{5}$
}

e-mail: primasatria@esaunggul.ac.id ${ }^{1}$, suryari.purnama@esaunggul.ac.id², riya.widayanti@esaunggul.ac.id ${ }^{3}$, lista.meria@esaunggul.ac.id ${ }^{4}$, deva.rivelino@raharia.info ${ }^{5}$

Primasatria Edastama, Suryari Purnama, Riya Widayanti, Lista Meria, \& Rivelino, D. (2021). The Potential Blockchain Technology in Higher Education Learning Innovations in Era 4.0. Blockchain Frontier Technology, 1(01), 104-113. Retrieved from

DOI: https://journal.pandawan.id/b-front/article/view/18

\begin{abstract}
In the world of education, the development of technology systems is increasingly rapid. The implementation of Blockchain continues to be used in various sectors. This study analyzed the use of Blockchain in higher education. The research discussion results lead to the use of blockchain technology, which is a new trend in higher education. Blockchain implementation in higher education creates problems in the use of blockchain technology. Based on the use of Blockchain in research, we are exploring the application of related technologies in higher education. The problem with technology that functions to record small transactions and data used for many sectors such as recording transactions, documentation, and even voting, which is also used in Higher Education, is unfortunately not well implemented. This supports research on the use of blockchain technology that can record transactions in many sectors. Documenting the process of transactions, documentation, and voting can even be used in Higher Education. To improve the blockchain technology system's performance in higher education, it is becoming more effective, efficient, and more accessible in recording transaction processes. It can become a new innovation for Higher Education.
\end{abstract}

Keywords: Higher Education, Learning Innovation, Blockchain, Digital Revolution 4.0.

\section{Introduction}

The new technology, Blockchain, is considered to revolutionize the learning process in the era of the industrial revolution 4.0 [1]. Before delving into Blockchain, we must understand the form of Blockchain, how it collects information, and the characteristics of its types. This ontology in education will be functional as a literature platform for basic and applied research that leads to the application and application of Blockchain in higher education [2]. Blockchain is a list of records that grow and are connected like a chain. Based on a global survey, it was determined that $80 \%$ of the limited knowledge and the application of blockchain technology should be able to be understood in more detail. Exploring blockchain technology can solve problems that focus on educational applications, where it can be successful if it highlights the features and advantages of blockchain technology [3]. 
The proposed application of blockchain technology to connect data on learning platforms will undoubtedly be a new movement that will further develop the world of education [4]. The philosophy of Blockchain technology is related to its ontology, and it can be characterized, applied, and realized by how it works in the world of education [5]. Of course, it will continue to grow over time because Blockchain can be considered a complex system. This research is the first step towards a more transparent and technologically advanced form of a higher education system [6]. This is a globally decentralized higher education credit [7]. The application and utilization of Blockchain in universities can be assessed to offer an integrated perspective globally for students and higher education institutions, and other.

\section{Research Method}

The method in this research uses descriptive methods and literature study. The illustrative way is a description of a problem that will be studied to provide information based on the research process's issues and the placement of appropriate information about the research problem to be carried out. The literature study method is a method that is driven by the similarity of topics or research themes, which aims to obtain theoretical aspects in collecting information and data through literature, books, expert opinion, and scientific journals [8]. Research collection with related themes is carried out so that it can become a means of further research. The following are 8 (eight) related literature studies, namely. We are creating and implementing blockchain technology to be used in voting on peer-to-peer networks with the success of sending block data from one node to another efficiently and quickly in terms of quality and security[9]. Blockchain technology can be helpful in an e-certificate system, where technology created using a distributed database with blockchain transaction data maintains security in the flow and privacy of data so that it is not easily imitated [9]. We are designing an electronic voting system that utilizes Blockchain technology in a website-based application. By utilizing blockchain technology, voting data results cannot be changed, duplicated or deleted [10]. The technology that works behind the scenes of cryptocurrencies like bitcoin and others is blockchain. The author aims to provide a simple description of blockchain implementation [11]

Blockchain technology is used to streamline identity management, create a tracking system, and identify product authenticity and is expected to synchronize data stored on the blockchain to all user networks, making the payment system more accessible, more efficient, and well documented. As well as making it easier for students, lecturers and others to process transactions [12]. The integration of blockchain technology growth is a trend that is very effective in the world of education. The compilation stages that originate from the time stamp in the new information box cannot be erased with minimizing the destruction of information and reducing the rate of fraud [13]. Edutech, which applies blockchain for learning facilities related to the 4.0 industrial revolution and can optimize the delivery of information currently still one-way in nature [14]. The learning method by turning it into a gamification concept that rests on blockchain technology. So this method compensates for the times when students prefer games to learning. Therefore this method can be applied to higher education [15]

\section{Result and Discussion}

\subsection{Basics}

Blockchain is where each block consists of separate transactions pooled together to form a continuous chain in the data set. Blockchain is referred to as a technological breakthrough that can be as important as the internet [16]. Whose identity is still unknown, introduced blockchain, which is part of its whitepaper for a new payment method for crypto transactions, namely bitcoin [17]. The white paper aims to submit an electronic payment system based on cryptographic evidence rather than trust, allowing two parties to transact directly with each other without a third party [18] Bitcoin's blockchain is the backbone, enabling decentralized payment methods. Currently, blockchain is used for other applications by corporate entities [19]. In the last decade, companies have started to utilize and implement blockchain technology in functions other than cryptocurrency. For example, Walmart has recently released essential steps to implement blockchain in its logistics process to ensure their fresh food is free from 
potential diseases such as E. coli and Salmonella [20]. Another example, Block Chart made by the Massachusetts Institute of Technology (MIT) and a company called Learning Machine [20]. Blockcerts use blockchain to collect certificates issued by selective higher education institutions to be accessed by users [21]. These are just two examples of how blockchain is used in industries other than cryptocurrency.

These blocks have about a $1 \mathrm{MB}$ data limit [22]. Another block is created for another transaction group, and the new block is linked to the previous block with a Merkle tree root hash and a parent block hash. The root hash of the Merkle tree connects the current block to the last block, and the parent block hash contains the hash of the previous block [23]. Called "Overlapping," this creates blockchain security because by doing so, one block is complete, so the block's contents are sealed and become indestructible [24]. Figure 2 provides a visual representation of the relationship between the previous and future (afterward) blocks.
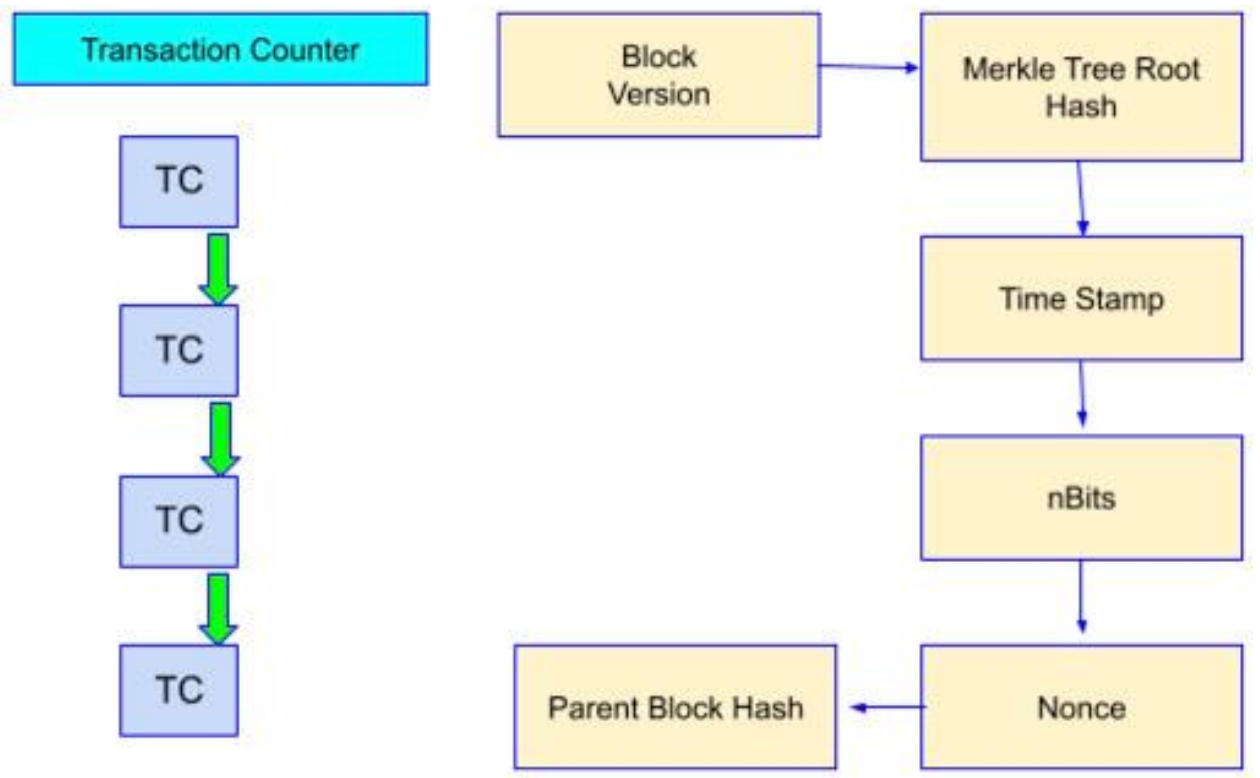

Source: Zheng et al., 2017

Figure 1. Block Structure and Its Component

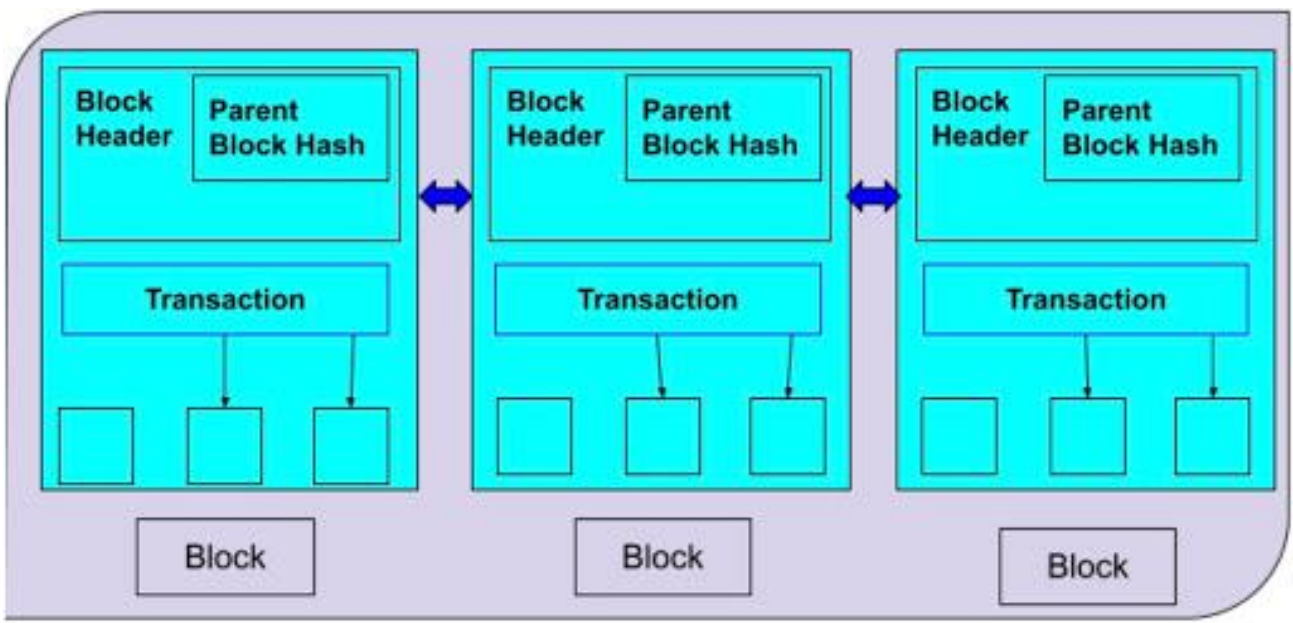

Source: Zheng et al., 201 ? 
Figure 2. Previous Block Relationships and The Future

As more and more blocks are added to the Blockchain, the new blocks are still connected to the genesis block [25]. Suppose the 1000th block in the Blockchain is linked to the previous block, and the 999th block is linked to the 998th block, and so on. So if someone tries and breaks any block or changes its components, the whole Blockchain gets altered. This makes it nearly impossible to modify or modify information or transactions on the Blockchain once it is approved and added to the Blockchain. However, to be added to the Blockchain, blocks undergo an extensive approval process.

\subsection{Approval Process}

Confirming a block means that the node has agreed to all transactions' authenticity in the newly created block and the underlying chain. Most of the blockchains currently in operation are public permissionless blockchains. The higher education blockchain must be a mix of public and private blockchains (consortium blockchain) [26]. due to Federal adjustment criteria. Public and private blockchains differ in their approval processes in semi-substantial ways, but it is essential to understand that both as educational blockchains will have components of both due to the use of individual, institutional and governmental adjustments [27]. In the Bitcoin public blockchain, the approval process is a very demanding operation on the computer [28]First, when someone wants to send a document to another user, a block is created online to represent the transaction. After that, the data is encrypted by a hashing algorithm (SHA-256) which converts the data into an irregular stack of digital information called a hash code. A hash code is a block of digital fingerprints with a computer hash code of 64 characters long. The hash code is always 64 characters on the computer, no matter $f$ it is for five or five hundred units. After the transaction is hashed, it is combined with other transactions into a block and is then validated [29]. There are two main approval processes used in blockchain, namely proof of work and proof of ownership.

Proof of stake protocols prefers mining to serve blocks by allowing them to "stake" a portion of their data on the network. The protocol randomly selects the validator from the entire betting pool, and the winner is given the ability to place the next block in the sequence [30]. This approval process allows for a more stable network than the proof-of-work approval process.

However, Proof-of-work (PoW) provides greater decentralization and liquidity than proof-of-stake (PoS) as mining continues to compete and are incentivized to do so. Proof-ofwork confirms transactions by having miners compete to solve mathematical equations to create new blocks and verify transactions. Proof-of-work (PoW) is the most common approval process. The miners are presented with several data pieces, including the SHA-256 hash that represents the previous block in the chain. They are also displayed with details of the current transaction that will be processed, such as a timestamp and other information that applies to that transaction. The mining task is to combine all this data into one hash and then produce what is known as evidence. This is done by trial and error because mining can only determine the evidence by trying all possible permutations until an answer is found [14].

No matter which approval process is used, once the block has obtained sufficient confirmation, the transaction is validated and placed on the blockchain as the next sequential block. The network then proceeds to validate/confirm all block transactions before they can be added to the ledger [27]. All blockchains have different levels of confirmation. After a new block is added to the blockchain, all miners (both proofs of work and proof of ownership) receive an updated copy of the blockchain [31]. This makes any differences clear quickly and adds security to the blockchain. And once a block is created and validated by the blockchain, it can never be destroyed or changed unless $51 \%$ of the blockchain agrees. if a verifiable change occurs, the difference will be simultaneously registered in the ledger and visible to all parties [13].

\subsection{Types of Blockchain}

The Bitcoin system is a public blockchain, but many other types of blockchains have been created since its creation. The current blockchain systems are categorized $n$ the following three main types: public, private, and consortium. Figure 3 llustrates the characteristics of each type of blockchain. 


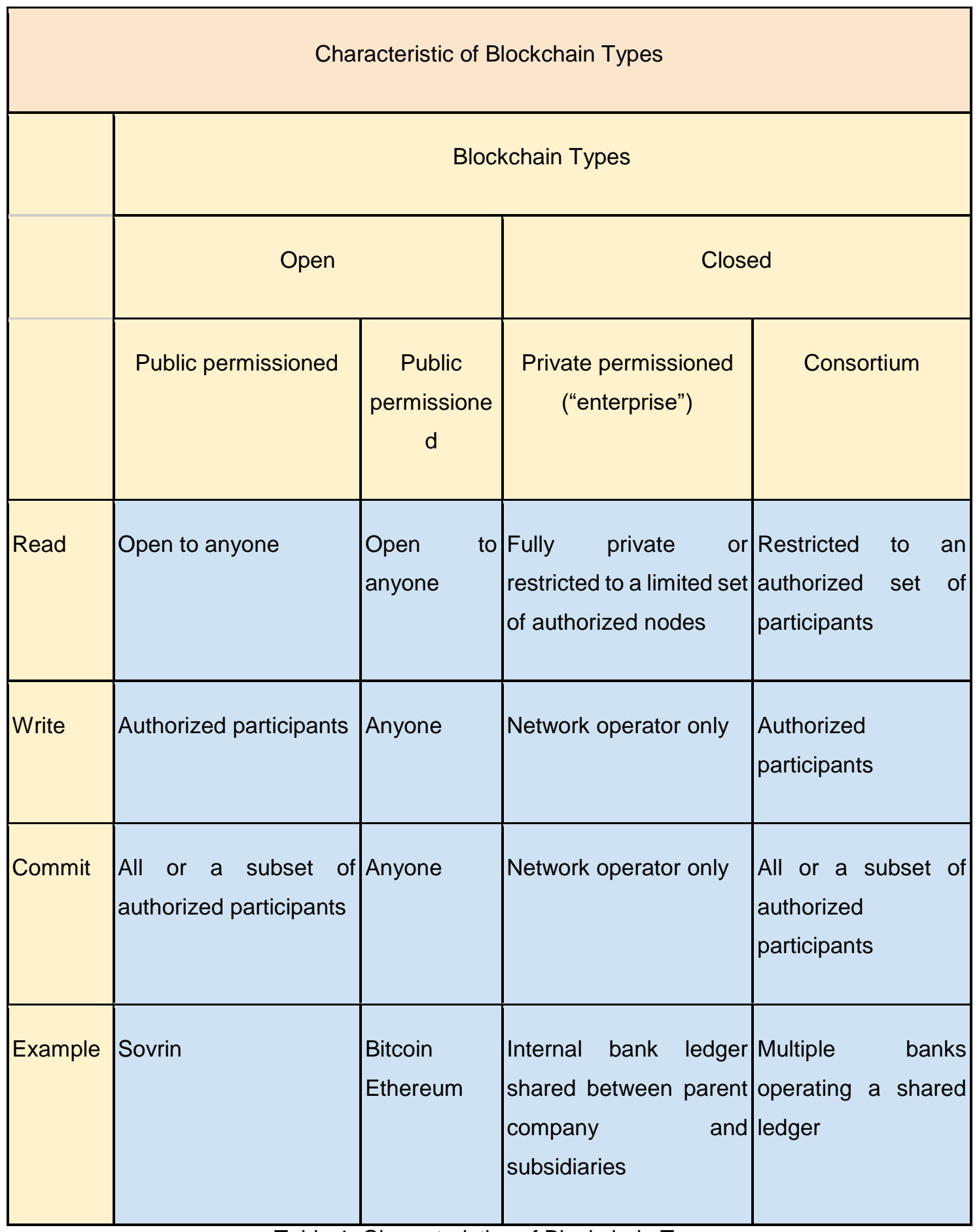

Table 1. Characteristics of Blockchain Types

In a public blockchain, all records are visible to the public, and everyone can participate in the consensus process [32]. This is an example of Blockchain, which is best known because cryptocurrencies use this type of Blockchain. However, there are two types of public Blockchain, 
namely without general permission and public permission [33]. A permissionless public blockchain is a type of Blockchain that is entirely decentralized. The public approval is open to anyone to view it, but only authorized participants have access to write (i.e., generate transactions and send them to the network) and perform (i.e., update ledger status) on the Blockchain.

A private blockchain, or unlicensed Blockchain, is where only nodes originating from one specific source can join the consensus process. individual participants must verify their identity and be approved by other Blockchain members [21]. Permissions remain centralized with a single organization, but the ability to read the Blockchain can be public or restricted to some extent. Since this type of Blockchain is centralized, the approval process is also centralized [33].

The biggest advantage of transactions on private blockchains is that they are much cheaper to process than other types. Setting up a minor scale blockchain in the form of a private blockchain allows members of this network to save time and reduce the energy consumed to verify and process activated transactions. This will enable transactions and organizations to interact faster and at a slower rate than public blockchains that require an extensive approval process in a proof of work and proof-of-stake model.

The consortium blockchain is one in which only a pre-selected group of nodes will participate in the consensus process. This type of Blockchain can be described as a mixture of private and public blockchains. Therefore, a consortium blockchain was built by several organizations; it is partly decentralized because only a fraction of the nodes will be selected to determine consensus. An example is a group of financial institutions that operate a collective consortium blockchain. Each financial institution uses a node where a predetermined majority must sign the block to be valid. The right to read the Blockchain may be public or restricted to participants.

\begin{tabular}{|c|c|c|c|c|c|c|}
\hline \multicolumn{7}{|c|}{ Different Types of Blockchain Properties } \\
\hline & $\begin{array}{c}\text { Consensus } \\
\text { determination }\end{array}$ & $\begin{array}{c}\text { Read } \\
\text { permission }\end{array}$ & Immutability & Efficiency & Centralized & $\begin{array}{l}\text { Consensus } \\
\text { process }\end{array}$ \\
\hline $\begin{array}{l}\text { Consortiu } \\
\text { m } \\
\text { Blockchain }\end{array}$ & $\begin{array}{l}\text { One } \\
\text { organization }\end{array}$ & $\begin{array}{ll}\text { Could } & \text { be } \\
\text { public } & \text { or } \\
\text { restricted } & \end{array}$ & $\begin{array}{ll}\text { Could } & \text { be } \\
\text { tampered } & \end{array}$ & High & Yes & Permissioned \\
\hline $\begin{array}{l}\text { Private } \\
\text { Blockchain }\end{array}$ & $\begin{array}{l}\text { Selected set of } \\
\text { nodes }\end{array}$ & $\begin{array}{ll}\text { Could } & \text { be } \\
\text { public } & \text { or } \\
\text { restricted } & \end{array}$ & $\begin{array}{ll}\text { Could } & \text { be } \\
\text { tampered }\end{array}$ & High & Partial & Permissioned \\
\hline
\end{tabular}




\begin{tabular}{|c|c|c|c|c|c|c|}
\hline $\begin{array}{c}\text { Public } \\
\text { Blockchain }\end{array}$ & All miners & Public & $\begin{array}{l}\text { Nearly } \\
\text { impossible to } \\
\text { tamper }\end{array}$ & Low & No & $\begin{array}{l}\text { Permissionles } \\
\mathrm{s}\end{array}$ \\
\hline
\end{tabular}

Table 2. Blockchain Properties

Figure 4 summarizes the three blockchain types and their various properties [26]. This image shows the multiple components of each blockchain type about other blockchain types. The photo shows how private blockchain and public blockchain are fundamentally opposites, with the blockchain consortium in the middle leaning slightly towards the private blockchain. Each of these types of blockchain has its pros and cons that make it adaptable to specific industries.

\subsection{Potential of Blockchains Higher Education}

Higher education is an industry in which blockchain has not been implemented on a large scale [34]. Conceivably, blockchain could transform higher education and fundamentally disrupt its operations. The immutable ledger, security, transparency, and overall time-saving capabilities offered by blockchain, higher education operations, and record-keeping functions can be changed dramatically and multiple administrative processes. Accessibility of these notes, grades, assignments; advising students on which classes to take; certification verification; and anything that deals with a student or institutional transactions and records will change the access, assessment, and security of education databases.

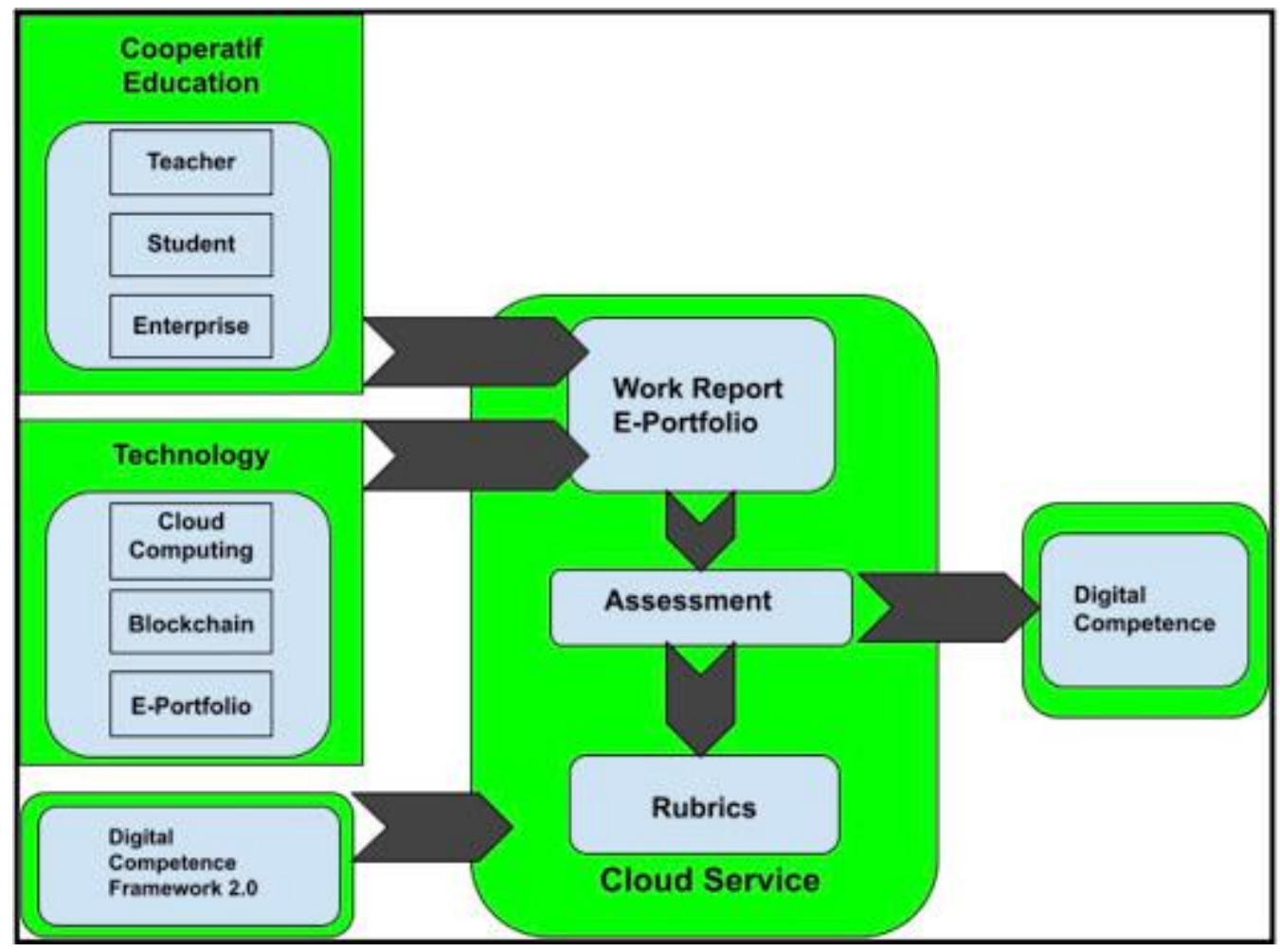

Figure 3. Conceptual Framework Design

Figure 3. The Conceptual Framework is based on a systems approach by dividing it into three elements: input, processing, and output. The input element consists of three stakeholders 
of cooperative education, technology, and digital competence framework 2.0. Cooperative education stakeholders include students, faculty, and workplace mentors. These technologies include E-Portfolios, cloud computing technology, and blockchain technology. The processing element consists of an assignment assessment process for digital competencies through the EPortfolio and recorded into the blockchain for increased reliability. The output element is the result of digital competence reliability that the labor market can consider for recruitment. The findings of the research paper investigation in the previous step were taken into consideration for the selected components according to the context, written reports $(100 \%)$, employer assessments (66.67\%), and integrated rubrics (44.44\%).

Written reports $\rightarrow$ Assignment reports in E-Portfolios.

Rubrics $\rightarrow$ transforming digital competence to assessment criteria of E-Portfolio

Employer assessment $\rightarrow$ E-Portfolio and /rubrics integration to assessment form.

The advantage of using blockchain technology in higher education is the ability to accumulate large enough data forever that is accurate, transparent, and ndelible. The blockchain block will contain all student records related to the admission process, completion of coursework, certificates, academic lab work, submitted research papers, internships, publications, exam data, quiz information, and others [3]. The information related to each class was pursued like the current digital recording system.

What is being proposed is an application where students can see whatever they need whenever needed. Students will log into the system with their email and password and review the database listing each course they have enrolled in. They will then click on a subject and view all completed assignments and view their associated grades. The blockchain will include papers, exams, and all assignments. System validation will include verification of academic fraud to prevent students from sharing old exam information with others. This can be anything from not allowing students to print exams or sending alerts when old exams open. Prospective employers can request to see multiple blocks of data. Students/alumni will submit confirmation to allow author access. This procedure allows potential employers to know more about each job applicant. imagine if you could see not only the applicant's transcript but the grades/evaluations that were obtained. This will create a better understanding for employers filling entry-level positions and eliminating the obligation to hire unqualified or inappropriate employees.

The blockchain will also help with the acceptance process. Instead of students who can't wait to hear about their student's application to enroll in the school of their choice, students can use the higher education blockchain of an app to upload the required documents and see the application process as it happens. For graduate students, blockchain includes admission documents, reference letters, entrance examination scores, and references to records in the undergraduate blockchain data. The graduate student block will be much broader to include publication work, presentations, theses, and dissertations in addition to honors, awards, or other related information relating to the academic performance of postgraduate students.

\section{Conclusion}

The use of blockchain technology in education is a promising new breakthrough in entering the era of the 4.0 revolution. The efficiency of using blockchain that has not been well realized is a challenge in its exploration process. There are 2 (two) problem descriptions that can be solved with 2 (two) conclusions, namely: First, Blockchain can provide a secure database for student test scores and data from the online learning system because it can track large amounts of information. In addition to publicly available information to all, personal information that would otherwise be inaccessible can be stored securely. Second, not only learning data, blockchain can also provide security for students, graduates, parents, teachers, and higher education institutions. This allows students / alumni to become registrars forever, where higher education certificates are guaranteed authenticity without requiring a long process in the verification stage. In other words blockchain provides a secure means for all parties to prove their credentials which allows people to use their education as currency in this modern world. With an increasing number of accredited 
education providers and a move towards a skills-based national economy, blockchain provides a way for individuals to gather evidence of learning and achievement that cannot be erased or violated. Unfortunately, the implementation of blockchain technology in education is still in the process of adjustment, given its lack of acceptance in society. Socialization about the benefits of implementing blockchain technology is needed.

\section{References}

[1] M. Hardini, Q. Aini, U. Rahardja, R. D. Izzaty, and A. Faturahman, "Ontology of Education Using Blockchain: Time Based Protocol," in 2020 2nd International Conference on Cybernetics and Intelligent System (ICORIS), 2020, pp. 1-5.

[2] A. Juliani, A. Mustadi, and I. Lisnawati, "'Make A Match Model' for Improving the Understanding of Concepts and Student Learning Results," Indones. J. Learn. Adv. Educ., vol. 3, no. 1, pp. 48-56, 2021.

[3] Q. Aini, U. Rahardja, N. P. L. Santoso, and A. Oktariyani, "Aplikasi Berbasis Blockchain dalam Dunia Pendidikan dengan Metode Systematics Review," CESS (Journal Comput. Eng. Syst. Sci., vol. 6, no. 1, pp. 58-66, 2021.

[4] E. P. Harahap, Q. Aini, and R. K. Anam, "Pemanfaatan Teknologi Blockchain Pada Platform Crowdfunding," Technomedia J., vol. 4, no. 2 Februari, pp. 199-210, 2020.

[5] R. A. Sukmawati, M. Pramita, H. S. Purba, and B. Utami, "The use of blended cooperative learning model in introduction to digital systems learning," Indones. J. Learn. Adv. Educ., vol. 2, no. 2, pp. 75-81, 2020.

[6] A. P. Christidamayani and Y. D. Kristanto, "The Effects of Problem Posing Learning Model on Students' Learning Achievement and Motivation," arXiv Prepr. arXiv2002.04447, 2020.

[7] A. C. Nugraha, "Penerapan Teknologi Blockchain dalam Lingkungan Pendidikan: Studi Kasus Jurusan Teknik Komputer dan Informatika POLBAN," Produktif J. IIm. Pendidik. Teknol. Inf., vol. 4, no. 1, pp. 15-20, 2020.

[8] Z. Fauziah, H. Latifah, U. Rahardja, N. Lutfiani, and A. Mardiansyah, "Designing Student Attendance Information Systems Web-Based," Aptisi Trans. Technopreneursh., vol. 3, no. 1, pp. 23-31, 2021.

[9] R. Hanifatunnisa and M. Ismail, "Desain dan Implementasi Sistem Pencatatan Pemungutan Suara dengan Teknologi Blockchain pada Jaringan Peer-to-Peer," J. Nas. Tek. Elektro dan Teknol. Inf., vol. 9, no. 4, pp. 354-364.

[10] M. Yusup, Q. Aini, D. Apriani, and P. Nursaputri, "PEMANFAATAN TEKNOLOGI BLOCKCHAIN PADA PROGRAM SERTIFIKASI DOSEN," in SENSITIf: Seminar Nasional Sistem Informasi dan Teknologi Informasi, 2019, pp. 365-371.

[11] S. D. K. Hu, H. N. Palit, and A. Handojo, "Implementasi Blockchain: Studi Kasus eVoting," J. Infra, vol. 7, no. 1, pp. 183-189, 2019.

[12] H. Yulianton, R. C. N. Santi, K. Hadiono, and S. Mulyani, "Implementasi Sederhana Blockchain," 2018.

[13] U. Rahardja, M. Hardini, A. L. Al Nasir, and Q. Aini, "Taekwondo sports test and training data management using blockchain," in 2020 Fifth International Conference on Informatics and Computing (ICIC), 2020, pp. 1-6.

[14] U. Rahardja, Q. Aini, M. Yusup, and A. Edliyanti, "Penerapan Teknologi Blockchain Sebagai Media Pengamanan Proses Transaksi E-Commerce," CESS (Journal Comput. Eng. Syst. Sci., vol. 5, no. 1, pp. 28-32, 2020.

[15] P. A. Sunarya, U. Rahardja, L. Sunarya, and M. Hardini, "The Role Of Blockchain As A Security Support For Student Profiles In Technology Education Systems," InfoTekJar J. Nas. Inform. dan Teknol. Jar., vol. 4, no. 2, pp. 203-207, 2020.

[16] Q. Aini, U. Rahardja, and A. Khoirunisa, "Blockchain Technology into Gamification on Education," IJCCS (Indonesian J. Comput. Cybern. Syst., vol. 14, no. 2, pp. 147-158, 2020.

[17] M. Sharples and J. Domingue, "The blockchain and kudos: A distributed system for educational record, reputation and reward," in European conference on technology 
enhanced learning, 2016, pp. 490-496.

[18] F. P. Oganda, N. Lutfiani, Q. Aini, U. Rahardja, and A. Faturahman, "Blockchain Education Smart Courses of Massive Online Open Course Using Business Model Canvas," in 2020 2nd International Conference on Cybernetics and Intelligent System (ICORIS), 2020, pp. 1-6.

[19] S. Nakamoto, "Bitcoin: A peer-to-peer electronic cash system Bitcoin: A Peer-to-Peer Electronic Cash System," Bitcoin. org. Dispon. en https//bitcoin. org/en/bitcoin-paper, 2009.

[20] S. Pelletier, "Blockchain in higher education," Chron. High. Educ. Oct., 2018.

[21] G. Crosley and A. Anderson, "The audit of the future: Daring, disruptive, and data-driven but poised to add significant value to firms and clients," Public Account. Rep., vol. 62, no. February, pp. 5-8, 2018.

[22] U. Rahardja, A. S. Bist, M. Hardini, Q. Aini, and E. P. Harahap, "Authentication of Covid19 Patient Certification with Blockchain Protocol," Int. J. Adv. Sci Technol, vol. 29, no. 8s, pp. 4015-4024, 2020.

[23] R. G. Wiatt, "From the mainframe to the blockchain," Strateg. Financ., vol. 100, no. 7, pp. 27-35, 2019.

[24] Q. Aini, U. Rahardja, M. R. Tangkaw, N. P. L. Santoso, and A. Khoirunisa, "Embedding a Blockchain Technology Pattern Into the QR Code for an Authentication Certificate," J. Online Inform., vol. 5, no. 2, pp. 239-244, 2020.

[25] J. Lindenmoyer and M. Fischer, "Blockchain: Application and Utilization in Higher Education,” J. High. Educ. Theory Pract., vol. 19, no. 6, pp. 71-80, 2019.

[26] Z. Zheng, S. Xie, H. Dai, X. Chen, and H. Wang, "An overview of blockchain technology: Architecture, consensus, and future trends," in 2017 IEEE international congress on big data (BigData congress), 2017, pp. 557-564.

[27] J. Murray, "The Coming World of Blockchain: A Primer for Accountants and Auditors," CPA J., vol. 88, no. 6, pp. 20-27, 2018.

[28] Q. Aini, N. Lutfiani, N. P. L. Santoso, S. Sulistiawati, and E. Astriyani, "Blockchain For Education Purpose: Essential Topology," Aptisi Trans. Manag., vol. 5, no. 2, pp. 112120, 2021.

[29] M. H. Fajar, "Quality of service ethereum blockchain berbasis IPFS untuk validasi ijazah sekolah." UIN Sunan Ampel Surabaya, 2020.

[30] D. Andayani, N. P. L. Santoso, A. Khoirunisa, and K. Pangaribuan, "Implementation of the YII Framework-Based Job Training Assessment System," Aptisi Trans. Manag., vol. 5, no. 1, pp. 1-10, 2021.

[31] Q. Aini, M. Budiarto, P. O. H. Putra, and N. P. L. Santoso, "Gamification-based The Kampus Merdeka Learning in 4.0 era," IJCCS (Indonesian J. Comput. Cybern. Syst., vol. 15, no. 1, pp. 31-42, 2021.

[32] J. Salmon and G. Myers, "Blockchain and associated legal issues for emerging markets," 2019.

[33] Z. Zheng, S. Xie, H.-N. Dai, X. Chen, and H. Wang, "Blockchain challenges and opportunities: A survey," Int. J. Web Grid Serv., vol. 14, no. 4, pp. 352-375, 2018.

[34] M. U. Noor, "Implementasi Blockchain di Dunia Kearsipan: Peluang, Tantangan, Solusi, atau Masalah Baru?," Khizanah al-Hikmah J. IImu Perpustakaan, Informasi, dan Kearsipan, vol. 8, no. 1, pp. 86-96, 2020. 